\title{
Reply to Doctor S. Özsoylu
}

\author{
Judith Janneke Korterink
}

Received: 21 October 2013 / Accepted: 22 October 2013 /Published online: 13 November 2013

(C) Springer-Verlag Berlin Heidelberg 2013

We thank Doctor Özsoylu for the constructive comment regarding our article [1]. We noted in the publication that in case of thrombocytopenia without any clinical sign, it is important to consider pseudothrombocytopenia (PTCP). PTCP could be confirmed by platelets counting performed in blood collected in $\mathrm{Na}$ citrate-containing tubes.

Dr. Özsoylu suggested adding peripheral smear examination to strengthen the diagnosis. PTCP is characterized by in vitro aggregation of platelets after blood collection [2]. Therefore, we agree with this comment. In the case of thrombocytopenia, review of a peripheral blood film is essential to confirm platelet aggregation (Fig. 1). Also in the case we described in our publication, microscopic examination of the blood films confirmed the platelet aggregation.

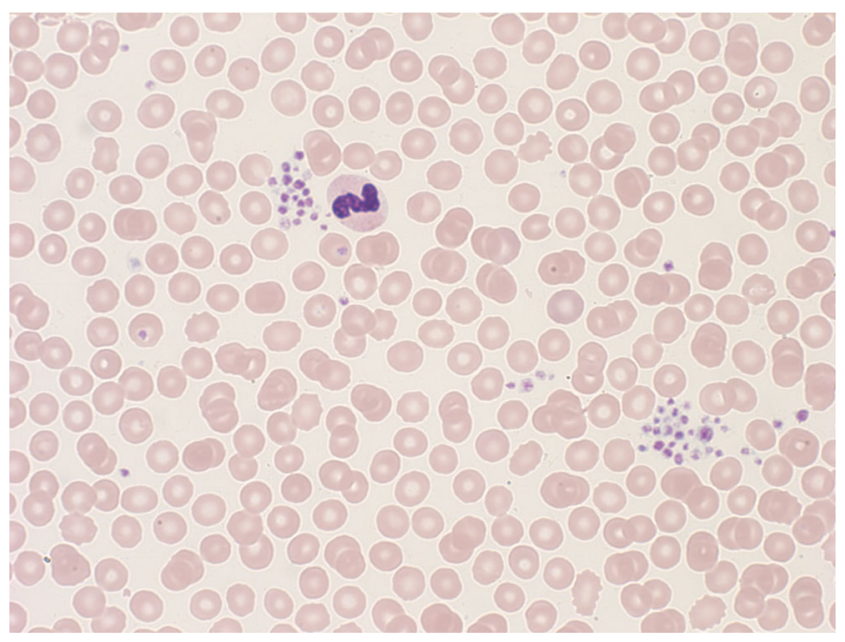

Fig. 1 Peripheral smear of platelet aggregation

J. J. Korterink $(\bowtie)$

Jeroen Bosch Hospital's, Hertogenbosch, Netherlands

e-mail: judithkorterink@hotmail.com

\section{References}

1. Korterink JJ, Boersma B, Schoorl M et al (2013) Pseudothrombocytopenia in a neonate due to mother? Eur J Pediatr 172(7):987-989

2. Shreiner DP, Bell WR (1973) Pseudothrombocytopenia: manifestation of a new type of platelet agglutinin 149. Blood 42:541-549 